\title{
Impacto da pandemia do COVID19 no Serviço de Saúde: uma revisão de literatura
}

\section{COVID19 Pandemic impact in the health care system: a literature review}

\author{
Edmara Laura Campiolo' \\ Henrique Kazuo Lima Kubo' \\ Gabriela Tiemi Ochikubo' \\ Gabriela Batista ${ }^{1}$
}

\section{INTRODUÇÃO}

Em dois de janeiro de 2020, um novo agente viral da família Coronaviridae (Cov), denominado como Severe Acute Respiratory Syndrome Coronavirus 2 ( SARS-CoV-2) [1], foi identificado como causador da doença classificada como Coronavirus Disease 2019 (COVID-19), responsável por um tipo de pneumonia viral [2]. Os primeiros casos foram informados à Organização Mundial de Saúde (OMS) em 31 de dezembro de 2019 e tiveram início na cidade de Wuhan - província de Hubei - na China [2]. Embora detalhes sobre o surgimento deste vírus permaneçam desconhecidos, os casos parecem ser resultado de transmissão humano-humano [3].

O vírus, denominado SARS-CoV-2 [1], responsável pela vigente pandemia, atingiu 187 países e pode causar manifestações clínicas graves [4]. O curso da doença permanece incerto, mas considera-se que seu potencial de gravidade seja suficiente para sobrecarregar a infraestrutura dos serviços de saúde, cuja demanda poderá implicar na necessidade de racionar os equipamentos e intervenções médicas [5].

Devido à dinâmica de transmissibilidade do SARSCoV-2, a identificação e o direcionamento de grupos de risco se tornam difíceis. O vírus é altamente infeccioso e possui um período de incubação que varia de 10 a 14 dias. A transmissão pode ocorrer durante a incubação assintomática ou enquanto a doença é imperceptível. Esses fatores criam problemas de controle que diferem daqueles associados às doenças transmissíveis já conhecidas, como varíola e tuberculose, que moldaram grande parte das leis e precedentes políticos que temos para ações restritivas de saúde pública [6].

A dificuldade de adaptação ao isolamento social como mecanismo de controle da doença já é evidente. O aumento das taxas de infecção e a mortalidade, associado a incerteza científica sobre o novo vírus, devem ser vistos como sinal de alerta à evolução da pandemia e como risco para os sistemas de saúde [6].

Considerando o surto de síndrome respiratória aguda pelo SARS-CoV em 2002 e o Middle East Respiratory Syndrome Coronavirus (MERS-CoV) em 2012, o SARS-Cov 2 é o terceiro coronavírus a surgir em humanos nas últimas duas décadas - uma emergência que colocou instituições globais de saúde pública em alerta máximo [5]. Os dados até agora sugerem que o vírus tem um risco de fatalidade em torno de $1 \%$, taxa mais grave do que a típica gripe sazonal, estando entre a pandemia de gripe de 1957 $(0,6 \%)$ e a pandemia de gripe de 1918 (2\%) [7].

As precauções indicadas para a assistência aos pacientes suspeitos ou confirmados de infecção pelo novo coronavírus são os seguintes equipamentos de proteção

\footnotetext{
${ }^{1}$ Faculdade São Leopoldo Mandic, Curso de Odontologia. Rua José Rocha Junqueira, 13, Swift, 13045-755, Campinas, SP, Brasil Correspondência para /

Correspondence to: AG FRANCO. E-mail: aalinebgfranco@yahoo.com.

${ }^{2}$ Universidade de Itaúna, Faculdade de Odontologia. Itaúna, MG, Brasil.
} 
individual (EPI): uso de máscara cirúrgica, óculos, avental e luvas de procedimento, além da higiene das mãos com agua e sabonete liquido (ou preparação alcoólica a 70\%). Caso seja necessário realizar um procedimento gerador de aerossóis, como por exemplo, intubação ou aspiração traqueal, faz-se necessária a troca da máscara cirúrgica para máscara N95 com peça facial filtrante número dois (PFF2), além da utilização de touca [8.

Dessa forma, enfrenta-se um contexto de falta de equipamentos de proteção individual, como nos Estados Unidos da América (EUA), em que foi reconhecida a aut para profissionais de saúde, sendo necessário reutilizar instrumentos primariamente de uso único [5], ou a indisponibilidade de testes suficiente para diagnosticar os pacientes [9].

Embora os esforços governamentais e privados se concentrem na obtenção e produção de ventiladores, os hospitais exigirão equipe capacitada para operar tais aparelhos As associaçôs hospitalares podem desenvolver estratégias para implantar as terapias respiratórias nos hospitais mais necessitados e desenvolver programas para treinar rapidamente os profissionais da área [10].

As medidas a serem tomadas diante de um crise incluem: resolver o problema imediatamente e evitar reincidência, melhorando a capacidade de enfrentar novos surtos [7]

\section{OBJETIVOS:}

O objetivo desta revisão de literatura é analisar o impacto da pandemia causada pelo SARS-Cov 2 no sistema de saúde brasileiro. Visa também verificar as possíveis formas de prevenir e/ou reduzir o colapso do sistema por falta de EPI para equipe profissional, além da falta de leitos e aparelhos ventiladores para pacientes em estado grave.

\section{METODOLOGIA:}

Para o desenvolvimento deste estudo foi realizada uma revisão de literatura descritiva, com abordagem qualitativa. Realizou-se uma pesquisa de busca bibliográfica na base de dados: PubMed, Scientific Electronic Library Online (SciELO), Biblioteca Virtual em Saúde (BVS).

Para os critérios de inclusão utilizados, foram selecionados 22 artigos publicados entre os anos de 2019

e 2020, com as palavras chave: Covid, Sistema Único de Saúde, Sistemas de Saúde, Coronavírus, Pandemia, presentes nos Descritores em Ciências da Saúde (DeCS), e que apresentassem estudos acerca do surto do novo coronavírus (COVID-19) relacic saúde. Foram excluídos os estudos que não estavam disponíveis gratuitamente, revisões de literatura, editoriais e aqueles não relacionados ao assunto ou que abrangiam somente um dos tópicos ("COVID-19" ou "Sistemas de saúde").

\section{RESULTADOS E DISCUSSÃO}

\section{ERANSMISSÁO}

Em 31 de dezembro de 2019 a China informou à Organização Mundial de Saúde (OMS) uma nova pneumonia viral na cidade de Wuhan, província de Hubei [2]. Essa pneumonia se espalhou rapidamente de uma única cidade para todo o país em apenas 30 dias. A velocidade da transmissão geográfica e o aumento repentino de casos surpreenderam e rapidamente sobrecarregaram os serviços de saúde pública na China 111. Em 24 de janeiro de 2020, menos de um mês do primeiro caso divulgado, pelo menos 830 casos foram diagnosticados em nove países [3].

O momento do surto de COVID-19, antes do feriado anual do Ano Novo Lunar da China, foi um fator importante, já que a China repensou como responder ao surto. Culturalmente, este é o maior e mais importante feriado do ano. É esperado que milhares de pessoas retornem às casas de suas famílias, resultando em várias mitas esse período, principalmente em aviões, trens e ônibus lotados Em 19 de fevereiro, a cidade de Cingapura tinha 84 casos de infecção por COVID-19, com resultados positivos por testes em tempo real de reação em cadeia da transcriptase reversa-polimerase (RT-PCR), com pesquisa dos genes $\mathrm{N}, \mathrm{S}$ e ORF1ab. Desses casos, 23 foram importados, incluindo 17 visitantes da China e seis cingapurianos que foram evacuados de Wuhan [2].

Segundo dados internacionais, até oito de maio de 2020, foram confirmados 4.006 .555 casos de COVID-19 com 275.755 óbitos. Os Estados Unidos da América são o país com maior número de casos e óbitos (1.318.787 e 78.503, respectivamente). O Brasil é o $8^{\circ}$ em número de casos confirmados e o $11^{\circ}$ em número de óbitos. No mesmo período, foram confirmados 145.328 casos por COVID-19 no Brasil. Deste total, $9.897(6,8 \%)$ foram a óbito, $76.134(52.4 \%)$ estão em acompanhamento e $59.297(40,8 \%)$ já se recuperaram da doença. Em 24 horas foram confirmados 10.222 novos casos da doença, o que representou um incremento de $7,6 \%(10.222 / 135.106)$ em relação ao total acumulado até o dia anterior [12]

Apesar do curso ainda incerto acerca da doença, a

COVID-19 pode causar dano suficiente para sobrecarregar a infraestrutura de serviços de saúde, criando demandas extraordinárias e sustentadas nos sistemas de saúde e no prestadores de serviços [5]

Dentre as razões pelas quais a COVID-19 é uma ameaça, destaca-se que pode matar, além de idosos com comorbidades, adultos saudáveis [7]. Os dados até agora sugerem que 0 vírus tem um risco de mortalidade em torno de $0,25 \%$ a $3,0 \%$, sendo mais grave que a típica gripe sazonal, cuja letalidade é de $0,1 \%[5 ; 7]$.

Além disso, a COVID-19 é transmitida com bastant eficiência. Em média, uma pessoa infectada espalha a doença para duas ou três outras, levando a uma taxa de aumento exponencial [5;7]. Alguns estudos mostraram um número de reprodução (R0) variando de 2 até 5,3 [13].

Também há fortes evidências de que pode ser transmitido por pessoas que são levemente doentes ou mesmo pré-sintomáticas. Isso significa que é muito mais difícil de ser contida do que a Síndrome Respiratória do Oriente Médio (MERS) ou Síndrome Respiratória Aguda Grave (SARS), nas quais ocorreram transmissão apenas por pessoas sintomáticas. De fato, a COVID-19 já causou 10 vezes mais casos que a SARS em um quarto do tempo [7].

Uma análise recente em larga escala da China sugere que $80 \%$ dos infectados são assintomáticos ou apresentam sintomas leves [5]. Se a infecção não causa quadros graves, as pessoas infectadas provavelmente não comparecerão a unidades de atendimento à saúde. Em vez disso, irão trabalhar e viajar, potencialmente espalhando o vírus para seus contatos e até em escala internacional [3] sendo uma consideração particularmente grave, tendc visto que o período de incubação atualmente estimado se estende de 2 a 12 dias [13].

Sendo assim, a falta de manifestações graves da doença afeta nossa capacidade de conter a propagação do vírus, dificultando a identificação de cadeias de transmissão e vigilância de casos de síndromes febris, como feito em surtos anteriores, como SARS-Cov e, mais recentemente, a doença pelo virus Ebola, Os quais foram contidos através da identificação de casos po contidos a sives da identificaça de casos por meio de consequente isolamento desses grupos [3].
Uma estimativa conservadora baixa é de que 5\% da população podem ser infectados dentro de 3 meses, mas o número exato de casos dependerá de varios do distanciamento social e outras intervenções [5]

\section{DISTANCIAMENTO SOCIA}

Uma redução significativa desses valores de R0 pode ser alcançada através da implementação de ações específicas de contenção, de acordo com os resultados de um estudo sobre a evolução das infecções detectadas na China [13].

A abordagem adotada pelo governo de Cingapura, por exemplo, baseado em sua experiência com a SARS, é que todos os casos confirmados são isolados até o resultado de duas amostras consecutivas para RTPCR (escarro ou swabs naso/orofaríngeos) se tornarem negativas. Os contatos próximos são identificados e os indivíduos sem sintomas ficam em quarentena por 14 dias a partir da última exposição [2]

Desde o seu início na Europa, a emergência do COVID-19 foi abordada através da implementação de medidas de contenção social. Isso é particularmente verdadeiro na Itália, o primeiro país europeu atingido por um importante surto. Em 4 de março de 2020, o governo nacional aprovou uma série de medidas importantes de limitação social, incluindo o fechamento de escolas e universidades, a quarentena de pessoas expostas, 0 pedido aos moradores que evitassem eventos lotados e iciou ações de rastreamento de contatos [13]

As medidas de saúde pública conhecidas por reduzir a disseminação viral, como distanciamento social, etiqueta da tosse e higiene das mãos, finalmente parecem ser uma prioridade nacional dos EUA e podem tornar a escassez de recursos menos severa, diminuindo a lacuna entre a necessidade médica e a oferta disponível de tratamentos

Por enquanto, soluções como trabalho inteligente remoto, videochamadas e comércio eletrônico representam alternativas que nos permitem continuar com nosso estilo de vida em alguns aspectos [13]

\section{SISTEMAS DE SAÚDE}

Considerando a dificuldade na contenção da disseminaçãa do vírus, as medidas de restrição adotadas pela Itália parecem mais focadas na diluicão do pico da epidemia en um periolo mis amplos primeros resultados dessas medidas seriam ganhar tempo para 
os preparativos no sistema de saúde, a fim de evitar sua sobrecarga e permitir um melhor gerenciamento dos pacientes infectados [13].

A demanda por serviços médicos avançados podem se aplicar a $20 \%$ do total infectado. Dos pacientes infectados pelo COVID-19, cerca de $15 \%$ têm doenças graves e $5 \%$ apresentam quadro crítico [5], necessitando de hospitalização em unidades de terapia intensiva [13]. No Brasil, o número mínimo de leitos de UTI para ser considerado adequado é de 10 leitos a cada $100 \mathrm{mil}$ habitantes [14].

Em um cenário brasileiro de $20 \%$ da população infectada, com $5 \%$ desses necessitando de cuidados em UTI por 5 dias, 294 das 436 regiões de saúde do país ultrapassariam a taxa de ocupação de $100 \%$. Dessas, $53 \%$ necessitariam ao menos do dobro de leitos-dia para tratar os casos mais críticos. Uma desaceleração da taxa de infecção populacional pode diminuir consideravelmente a superlotação consequente [14].

As taxas de mortalidade de casos são muito mais altas para populações vulneráveis, como pessoas com mais de 80 anos (> 14\%) e com comorbidades (10\% para aqueles com doenças cardiovasculares e $7 \%$ para aqueles com diabetes) [5]. 30\% das regiões de saúde do Brasil, com destaque para o Sudeste e Nordeste, são particularmente vulneráveis, devido a uma combinação de infraestrutura de leitos de UTI aquém do mínimo mortalidade por condições similares aO COVID-19 acima da mediana nacional [14].

$\mathrm{Na}$ Coreia do Sul, enfrentou-se uma escassez de leitos hospitalares, com alguns pacientes morrendo enquanto aguardavam a admissão [5]

Ademais, cirurgias eletivas foram canceladas, os procedimentos semieletivos adiados e salas de operações transformadas em UTIs improvisadas. Com todos os leito ocupados, pacientes foram acomodados em corredores e áreas administrativas [9].

No Brasil, ainda há outro problema a enfrentar, o mapeamento da situação de infraestrutura em saúde no Brasil evidencia enorme heterogeneidade regional escassez de recursos na maioria das regiões do país [14].

No país, têm-se 15,6 leitos de UTI por 100 mil habitantes, sendo a média no SUS de 7,1. Em $72 \%$ das regiôes de saúde, o número de leitos de UTI pelo SUS é inferior ao considerado adequado em um ano típico isso corresponde a $56 \%$ da população brasileira total e $61 \%$ da população sem cobertura de planos privado de saúde. Um padrão similar é observado com relação a ventiladores e respiradores [14].

Das 316 regiões de saúde com número de leitos de UTI pelo SUS abaixo do mínimo, 142 regiões não possuem leito algum, e se concentram no Norte, Nordeste e Centro-Oeste. Esses números contrastam com o padrão nas demais áreas do país. Menos de 1,0\% da população atendida pelo SUS na região Sul e 3,6\% na região Sudeste residem em regiões sem leitos de UTI [14]

Sobre a capacidade do sistema de saúde americano, mesmo uma estimativa conservadora mostra que a demanda criada pela pandemia de coronavirus vai muito além da capacidade dos hospitais dos EUA, destacando ventiladores em si, mas terapeutas respiratorios sauda de e equipe cuidados in equas com segurança em três turnos diarios [5]. Contribuindo para a escassez, destaca-se a intubação prolongada que muitos desses pacientes necessitam - geralmente 15 a 20 dias em ventilação mecânica, e, tipicamente, ento [9]. Também é provável que afete

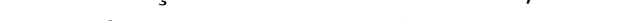
quarentena [5] Jovens médicos tem trabar las ou em de frente, com turnos extras e fora de suas especialidades [9].

No Reino Unido, milhares de estudantes de medicina se formarão antecipadamente e poderão começar a trabalhar como médicos juniores. Os médicos que se aposentaram nosúltimos três anos estão sendo solicitados em educaça, pesquisa ou ins hão são inentivados a retornaraça, pesquisa ou inspeçăo săo incentivados a retoris a equipe clinica pode ser transferida de especialidades para as areas de maior necessidade, com treinamento adicional fornecido rapidamente, conforme necessário. O governo também estuda a possibilidade de recorrer aos conhecimentos Iogísticos e médicos do exército para apoiar hospitais [15]

Esse contexto todo implica em propostas como a de direcionar leitos de terapia intensiva e ventiladores, para pacientes que podem se beneficiar mais do tratamento, como foi feito na Itália [5].

O governo italiano estabeleceu um aumento de $50 \%$ no número de leitos em áreas críticas do hospital e um acordo de distribuição de pacientes entre instituições de saúde com o objetivo de evitar o colapso de alguns hospitais afetados por um maior afluxo de pacientes infectados [13].

Além do alto custo para montar e equipar um leito de UTI, que varia entre $R \$ 120.000,00$ a $R \$ 180.000,00$, há baixa disponibilidade no mercado de equipamentos médicos, como respiradores, devido à alta demanda global [14]

Como alternativa emergencial para reduzir custos e ganhar rapidez, alguns países estão montando hospitais exclusivos para tratamento de pacientes com infecção respiratória por COVID-19, e contratando ou requisitando leitos no setor privado [14].

E essencial identificar regiões mais vulneráveis, otimizar o uso de servicos existentes e dimensionar recursos que serão necessarios para fortale capacidade de resposta do sistema de saúde em regionat e local. Mais do que nuca serao necessatios esforços de regulação, coordenação e integração de ações entre entes da federação [14].

\section{SAÚDE DOS TRABALHADORES}

A maioria dos trabalhadores de saúde que atua no atendimento direto (face-a-face) com pacientes e usuários terá maior chance de contato com pessoas portadoras de COVID-19 e, consequentemente, de se infectar [16]. Isso dependerá de múltiplos fatores como: atividade que executa, duração da jornada de trabalho, quantidade de pessoas que atende, além do uso de Equipamentos de Proteção Individual, incluído a paramentação, retirada, higienização (quando não for descartável) e descarte correto destes equipamentos. Outro ponto importante segurança e saúde relativas ao ambiente de trabalho, possibilitando-os realizar suas atividades de modo a cuidar da sua saúde e da saúde dos outros. Além desses aspectos básicos, há que se garantir jornadas de trabalho e número de profissionais compatíveis com a demanda psíquica e física da função, além de adequado monitoramento Em um momento de Emergência de mpreendido que muitos profissio estão extrapolando jornadas formais e indo além para poder salvar vidas, mas é essencial que paradas entre turnos ou jornadas sejam preservadas e realizadas [17]

A Lei Orgânica do SUS, $n^{\circ} 8.080$, de 19 de setembro de 1990 [18], garante a promoção e proteção da saúde dos trabalhadores submetidos aos riscos e agravos advindos das condições de trabalho, bem como a recuperação, reabilitação e assistência às vítimas de acidentes doenças e agravos relacionados ao trabalho [17].

A ocorrência de uma morte confirmada ou suspeit por COVID-19 prevê protocolos específicos, visando o registro adequado da causa do óbito. Ademais, devido a chance existente de contaminação pelo SARS-CoV-2, todos os profissionais envolvidos devem tomar as medidas de biosseguranca neceśrias no manejo dos corpos das vítimas [12]

Em geral, os equipamentos de proteção individual (EPIs) que devem ser disponibilizados pelos serviços e utilizados pelos profissionais de saúde responsáveis pelo atendimento de casos suspeitos ou confirmados de COVID-19 são: 1) gorro; 2) óculos de proteção ou protetor facial: 3) máscara); 4) avental impermeável de mangas tipo de máscara, para procedimentos geradores de goticulas utilizar a máscara cirurgica e utilizar as de proteção respiratória (respirador particulado) com eficácia

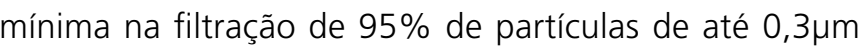
(tipo N95, N99, N100, PFF2 ou PFF3) sempre que realizar procedimentos geradores de aerossóis como por exemplo, intubação ou aspiração traqueal, ventilação não invasiva, ressuscitação cardiopulmonar, ventilação manual antes da intubação, indução de escarro, coletas de amostras nasotraqueais e broncoscopias [17].

Excepcionalmente, em situações de carência de insumos e para atender a demanda da epidemia da COVID-19, as máscaras de proteção respiratória (N95/ PFF2 ou equivalente) poderão ser usadas por período maior ou por um número de vezes maior que o previsto pelo fabricante, desde que pelo mesmo profissional e Cumpridos todos os cuidados necessários [8]

Além disso, a máscara cirúrgica não deve ser sobreposta à máscara N95 ou equivalente, pois além de não garantir proteção de filtração ou de contaminação, também pode levar ao desperdício de mais um EPI, o que pode ser muito prejudicial em um cenário de escassez [8].

\section{SAÚDE MENTAL}

A preocupação com a saúde mental da população aumenta no desenrolar de uma grave crise social. Essa pandemia pode ser descrita como uma dessas crises, a qual tem se qualificado como um dos maiores problemas de saúde pública mundial das últimas décadas. Um acontecimento como esse ocasiona problemas sociais e psíquicos que afetam a capacidade de enfrentamento de toda a sociedade, em variados níveis de intensidade e propagação [19].

Cuidar da saúde mental dos trabalhadores da Cuidar da saude mental dos trabaladores da pandemia da COVID-19 é essencial para a segurança dos 
trabalhadores e dos pacientes. Será muito frequente que estes profissionais se sintam em sofrimento emociona diante dessa situação, o que não significa que eles não possam continuar fazendo seu trabalho ou que isso seja uma fraqueza. Gerenciar a saúde mental dos profissionais e o bem-estar psicossocial durante esse período é tão importante quanto gerenciar sua saúde física principalmente para que eles possam ter melhor capacidade de cumprir seus papéis e desenvolver suas atividades [20]

Os profissionais de saúde, da ação estratégica "O Brasil Conta Comigo", que estão na linha de frente no combate ao COVID-19, têm disponível suporte psiquiátrico ofertado pelo Ministério da Saúde. Essa medida vis cuidar da saúde mental dos profissionais contratados pelo Governo Federal para auxiliar os gestores do Sistema Único de Saúde (SUS) nas ações de enfrentamento à pandemia nos estados [21].

\section{MEDICAÇÕES E VACINA}

O potencial para causar perturbações nos sistemas de saúde pública e acarretar perdas econômicas globalmente justifica a resposta agressiva, destinada a rastrear e diagnosticar todos os pacientes infectados e assim, quebrar a cadeia de transmissão de COVID-19 [3]. Entretanto, somados à dificuldade de vigilância, os métodos de triagem mais fáceis baseados na execução de um swab nasofaríngeo exibiram resultados falsode un swab nasofaringeo ntomáticos mplexo interceptar possíveis indivíduos infectados [13]

Além disso, intervenções diagnósticas, terapêuticas e preventivas são escassas. Produtos farmacêuticos como cloroquina, remdesivir e favipiravir estão passando por ensaios clínicos e outros tratamentos experimentais estão em estágios iniciais de estudo. Mesmo que um deles se mostre eficaz, o aumento da oferta levará tempo [5]

A escassez de medicamentos em geral também é uma realidade que pode estar ligada ao aumento da demanda às dificuldades de transporte nas áreas mais afetadas pela emergência. Globalmente, poderia haver uma redução notável na capacidade de produção, pela interrupção do trabalho para procedimentos de higienização ou quando cientistas, gerentes e trabalhadores adoecem com o vírus. Além disso, é sabido que os fabricantes de medicamentos dependem fortemente de ingredientes chineses [13].

A implicação do contexto chinês pode abranger cerca de 150 medicamentos prescritos, além de 63 empresas identificadas pelo Food and Drug Admnistration (FDA) que são responsáveis pelo fornecimento de dispositivos médicos essencia

Atualmente, mais de 15 vacinas estão em andamento, mas nenhuma está prevista para estar disponível antes do terceiro trimestre de 2020 [13], pois levará tempo para produzir, distribuir e administrar. Outros suprimentos e equipamentos médicos críticos, como equipamento de proteção individual (EPI), já são escasos [5], sendo que a chamada "compra de pânico" tem contribuído pela escassez de desinfetante para as mãos e máscaras faciais, por exemplo [13]

\section{ETICA E RACIONAMENTO}

No contexto de pandemia, em que a disponibilidade de recursos não é capaz de suprir a demanda, as equipes de atendimento têm que lidar com a tarefa de direcionar o tratamento disponível para determinados pacientes em virtude de outros [5]. Tal realidade vivenciada nos hospitais da Itália, considerava, além do número de comorbidades do paciente, a gravidade da insuficiência respiratória e sua probabilidade de sobreviver à intubação prolongada, com o objetivo de dedicar seus recursos limitados àqueles que se beneficiariam mais, com maior chance de sobreviver [9].

Para a tomada de decisões, é importante que haja uma equipe com experiência em enfermagem e terapia respiratória, que defina a alocação de recursos e comunique à equipe clínica, ao paciente e à família [9]. Médicos que não atuem no atendimento direto ao paciente ou comitês de ética podem ser úteis para ajudar a aplicar diretrizes, avaliando a situação, nas decisões de racionamento e implementação de escolhas definitivas [5].

A questão é, como conduzir de forma ética e consistente, em vez de basear as decisões nas abordagens de instituiç̃os individuais ou na intuição de um medico alocar recursos médicos na pandemia incluem maximizar benefícios, com base na administração responsável dos recursos. A prioridade, em casos de recursos limitados, deve ter como objetivo salvar o maior número de vidas e com o máximo de melhorias na duração da vida dos indivíduos pós-tratamento [5]

Uma segunda recomendação, acerca de intervenções críticas, como testes, EPI, leitos de UTI, ventiladores, terapêutica e vacinas, os quais devem ser direcionados primeiramente aos profissionais de saúde da linha de

\section{INFORMAÇÃO}

Como exemplo a ser seguido, Taiwan divulgou informações precisas, de forma rápida e acessível. Além dos comunicados diários de imprensa do ministro da Saúde, o vice-presidente, um epidemiologista, fez regularmente anúncios de serviço público transmitidos do gabinete do presidente e que foram disponibilizados via internet. Esses anúncios incluíam quando e onde usar máscaras, a importância da lavagem das mãos e o perigo de estocar máscaras para impedir que elas se tornem indisponíveis para os profissionais de saúde da linha de frente [22].

Na Itália um hospital, recebeu um memorando que proíbe entrevistas à imprensa, a fim de evitar causar alarme público adicional. No entanto, minimizar a gravidade da situação estava tendo consequências letais [9].

Assim, faz-se necessário, investir na vigilância de doenças, através de um sistema integrado de informaç̧oes, incluindo um banco de dados instantaneamente acessivie a organizações relevantes, exigindo que os países compartilhem informação, enfrentando obstáculos diplomáticos e orçamentários [7]

Precisamos desenvolver plataformas seguras, para que revisões regulares possam acontecer rapidamente, facilitando o desenvolvimento de antivirais e vacinas, que envolvem enormes ensaios clínicos e licenciamentos que podem atravessar fronteiras nacionais [7].

\section{ECONOMIA}

Nossa dinâmica de vida é profundamente influenciada pelas medidas de contenção e, pela primeira vez no século 21, estamos enfrentando uma emergência de saúde em escala global [13]. Enquanto soluções como trabalho inteligente remoto, videochamadas e comércio eletrônico nos permitem continuar com nosso estilo de vida até certo ponto, outros aspectos de nossa sociedade, como nossa economia global conectada a cadeias de suprimentos de importação cruciais, estão sendo profundamente afetados [13]

Nesse sentido, é necessário financiamento governamental para superar a crise vigente, porque os produtos pandêmicos são investimentos extraordinariamente de alto risco, sendo necessários bilhões de dólares para combatê-la [7].

Os Estados devem ter acesso a listas de suprimentos a serem estocados ou redirecionados em caso de emergência. Além disso, os governos e a indústria precisarão chegar a um acordo, uma vez que durante

\section{CONCLUSÃO}

Tendo em vista o cenário atual, é possível avaliar que investimentos proativos em infraestrutura e capacidade de saúde pública são cruciais para responder efetivamente a epidemias como a do COVID-19, e é essencial continuar melhorando a vigilância internacional, cooperação, coordenação e comunicação sobre esse grande surto e estar ainda melhor preparado para responder a futuras ameaças à saúde pública [11].

\section{REFERÊNCIAS}

1. Pan American Health Organization / World Health Organization. Epidemiological Alert: Novel coronavirus (nCoV). 16 January 2020, Washington, D.C.: PAHONHO; 2020

2. Wong JEL, Leo YS, Tan CC. COVID-19 in Singapore-Current Experience: Critical Global Issues That Require Attention and Action JAMA 2020:323(13):1243-1244 doi:10.1001/ jama.2020.2467(COVID-19inSingapore-CurrentExperience) 3. MJ Vincent - A Novel Coronavirus Emerging in China - Key Questions for Impact Assessment

4. CoronavirusCOVID-19GlobalCasesbytheCenterforSystems Science and Engineering (CSSE) at Johns Hopkins University (JHU)». ArCGIS. Johns Hopkins CSSE. Consultado em 09 de maio de 2020. https://www.arcgis.com/apps/opsdashboard/ 5. Ezekiel J. - Fair Allocation of Scarce Medical Resources in the Time of Covid-19 6. Erin P. Fraher. Et al. Ensuring and Sustaining a Pandemic Workforce. NEJM. 2020. p2006376 7. BILL GATES- Responding to Covid-19 8. Brasil. ANVISA - Agência Nacional de Vigilância Sanitária. Nota Técnica no 04/2020 GVIMS/ GGTES/ ANVISA. Orientações para Serviços de Saúde: medidas de prevenção e controle que devem ser adotadas durante a assistência aos casos suspeitos ou confirmados de infecção pelo novo coronavírus. 2020. Disponível em: http://portal.anvisa.gov.br/ documents/33852/271858/ 
Nota+T\% C $3 \%$ A 9cnica+n+04-2020+GVIMS-GGTESANVISA ab598660-3de4-4f14-8e6f-b9341c196b28

9. R. Lisa - Facing Covid-19 in Italy - Ethics, Logistics, and Therapeutics on the Epidemic's Front Line

10. David M. Studdert, L.L.B., Sc.D., Mark A. Hall, J.D. Disease Control, Civil Liberties, and Mass Testing - Calibrating Restrictions during the Covid-19 Pandemic. NEJM. 2020. p2007637

11. Zunyou Wu. Jennifer M. McGoogan. Characteristics of and Important Lessons From the Coronavirus Disease 2019 (COVID-19) Outbreak in China. JAMA, feb 2020

12. BOLETIM EPIDEMIOLÓGICO ESPECIAL - 15 SE 19 - 08 de maio de 2020. Disponível em: https:// portalarquivos.saude.gov.br/images/pdf/2020/ May/09/2020-05-06-BEE15-Boletim-do-COE.pdf

13. V. Daniele Leonardi - The healthcare and pharmaceutical vulnerability emerging from the new Coronavirus outbreak

14. B. Rache, , Rocha, R., Nunes, L., Spinola, P., Malik, A. M. e A. Massuda (2020). Necessidades de Infraestrutura do SUS em Preparo ao COVID-19: Leitos de UTI, Respiradores e Ocupação Hospitalar. Nota Técnica n.3. IEPS: São Paulo.

15. W. John et al. Challenges for NHS hospitals during covid-19 epidemic. BMJ, mar 2020

16. Organização Mundial de Saúde - OMS. Coronavirus disease (COVID-2019) situation reports. Disponível em: https://www.who.int/emergencies/ diseases/novel-coronavirus-2019/ situation-reports.

17. BRASIL. Ministério da Saúde. Recomendações de proteção aos trabalhadores dos serviços de saúde no atendimento de COVID-19 e outras síndromes gripais. Disponível em: https://portalarquivos.saude.gov.br/images/ pdf/2020/April/16/01-recomendacoes-de-protecao.pdf

18. BRASIL. Lei $\mathrm{n}^{\circ}$ 8.080, de 19 de setembro de 1990. Lei Orgânica da Saúde. Brasília, 1990.

19. F. André, et al. COVID-19 e saúde mental: a emergência do cuidado.Estudos de Psicologia (Campinas). Vol. 37. Jun, 2020
20. OSHA - Occupational Safety and Health Act. Guidance on Preparing Workplaces for COVID-19. 2020. Disponível em: $\quad$ https://www.osha.gov/Publications/OSHA3990.pdf

21. Profissionais de saúde contam com suporte psiquiátrico no SUS. Disponível em: https://www.saude. gov.br/noticias/agencia-saude/46858-profissionaisde-saude-contam-com-suporte-psicologico-no-sus

22. C. Jason Wang. Et al. Response to COVID-19 in Taiwan. Big Data Analytics, New Technology, and Proactive Testing. JAMA, Mar 2020 